\title{
EFEITOS DA UTILIZAÇÃO DOS SUBPRODUTOS ALGODOEIROS NA DIETA DE PRÉ-RUMINANTES
}

\author{
André Giarola Boscarato ${ }^{1}$, Rita de Cassia Lima Ribeiro ${ }^{2}$, \\ Jessé Lahos Borges ${ }^{3}$, Ranulfo Piau Junior ${ }^{4}$, Vanderson dos Santos Silva ${ }^{5}$. \\ 1. Médico Veterinário, Doutorando do Programa em Ciência Animal com ênfase em produtos \\ bioativos da UNIPAR. Praça Mascarenhas de Moraes n. 4282, Zona 3. Umuarama - Paraná \\ - Brasil. \\ 2. Médica Veterinária, Docente do curso de Medicina Veterinária da UNIPAR \\ 1Doutorando em Ciência Animal com ênfase em produtos bioativos pela \\ Universidade Paranaense \\ 3.- Médico Veterinário, Doutorando do Programa em Ciência Animal com ênfase em \\ produtos bioativos da UNIPAR. \\ 4.Docente do programa de pós-graduação em Ciência Animal com ênfase em \\ produtos bioativos pela Universidade Paranaense, email: piau@prof.unipar.br \\ 5Academico de Medicina Veterinária pela Universidade Paranaense, Paraná - Brasil. \\ Recebido em: 22/09/2018 - Aprovado em: 23/11/2018 - Publicado em: 03/12/2018 \\ DOI: 10.18677/EnciBio_2018B40
}

\begin{abstract}
RESUMO
A nutrição de ruminantes a base de subprodutos do algodão é uma importante fonte energética e proteica; porém, há nesses subprodutos um composto antinutricional, o gossipol, que é tóxico para os animais monogástricos e pré-ruminantes. O presente trabalho relata a morte de um bezerro de 25 dias de idade, tratado com ração que continha em sua composição caroço e farelo de algodão. $O$ animal chegou ao Hospital Veterinário da Universidade Paranaense - UNIPAR apresentando icterícia de mucosas, desidratação, letargia e sons pulmonares alterados, vindo a óbito no mesmo dia. Este foi levado para necropsia, a qual mostrou hidrotórax, hidroperitôneo, icterícia de subcutâneo acentuado, edema pulmonar, coração com fibrina, espessamento de saco pericárdio, hepatomegalia e aumento de linfonodos; o histológico apresentou necrose e infiltrado inflamatório em tecidos cardíaco e hepático. Os sinais clínicos e os achados pós-morte foram compatíveis com experimentos de autores que trabalharam com bezerros e ovinos jovens; outros estudos envolvendo a toxicidade do gossipol foram considerados. Pré-ruminantes alimentados com subprodutos de algodão podem apresentar intoxicação clinica por gossipol.
\end{abstract}

PALAVRAS-CHAVE: algodão; coração; fígado; gossipol; intoxicação; pulmão.

\section{EFFECTS OF THE USE OF COTTON BY-PRODUCTS IN THE PRE-RUMINANTS DIET}

\begin{abstract}
Nutrition of ruminants based on cotton byproducts is an important source of energy and protein; already, there are by-products an antinutritional compound, gossypol, which is toxic to monogastric and pre-ruminant animals. The present work reports the
\end{abstract}


death of a 25-day old calf, treated with ration that contained in its composition seed and cotton meal. The animal arrived at the Veterinary Hospital of the University of Paraná - UNIPAR with jaundice of mucous membranes, dehydration, lethargy and altered pulmonary children, and died the same day. This was carried out for necropsy, increased hydroperitone, hydroperitoneum, marked subcutaneous jaundice, pulmonary edema, fibrin heart, pericardial sac thickening, hepatomegaly and enlarged lymph nodes; the histological advanced necrosis and inflammatory infiltrate in cardiac and hepatic tablets. Clinical signs and postmortem findings were compatible with the work of authors who functioned as calves and young sheep; other studies involving gossypol toxicity were considered. Pre-ruminants fed cotton by-products may present clinical gossypol intoxication.

KEYWORDS: cottonseed, gossypol, heart, intoxication, liver, lung.

\section{INTRODUÇÃO}

Com o intuito de formular rações com menores custos - para maximizar os lucros - as empresas buscam utilizar subprodutos como o farelo de algodão (YUE; ZHOU, 2008). Este subproduto é considerado a terceira fonte de proteína vegetal devido a sua quantidade e sua ampla disponibilidade pelo mercado (EL-SAIDY; GABER, 2004). Além da redução dos custos na composição da ração (GADELHA et al., 2011; MARSíGLIO, 2015), possui boa composição nutricional (ROGÉRIO et al., 2003; MOREIRA, 2008; PAIM et al., 2010).

Moreira (2008), comparou composições bromatológicas do caroço do algodão, e relatou uma média de $22 \%$ de proteína bruta (PB) na sua composição. Para Cardoso (1998), até $50 \%$ de sua PB é de proteína não degradável no rúmen (PNDR). A autora ainda aponta que o caroço utilizado na alimentação animal deve conter alguma porcentagem do línter, que é uma fibra curta, retida no caroço após a retirada da pluma e é facilmente digestivo para os ruminantes, assim, não se deve utilizar o caroço cujo línter seja totalmente retirado, pois isso exige um processo químico, que destina o caroço para a preparação da semente. Apesar da conveniência que é a utilização dos subprodutos do algodão, alguns estudos têm alertado para a toxicidade existente em uma substância presente nesta planta - o gossipol (GADELHA et al., 2011, PIAU JUNIOR et al., 2016).

O Gossipol é um composto polifenólico de cor amarela existente nas hastes, folhas e sementes de algodão, o qual foi isolado pela primeira vez em 1899 (BLANCO, 2008). Este composto é observado de duas formas - a forma "livre" e a "ligada" às proteínas, principalmente ao aminoácido lisina. A forma "ligada" não é tóxica porque não é absorvida na digestão e a forma "livre" pode ser tóxica por atuar diminuindo a capacidade de transporte de oxigênio no sangue. O farelo torna-se menos tóxico do que o caroço do algodão devido ao aquecimento que faz com que parte se apresente de forma ligada (MARSÍGLIO, 2015).

Este composto pode ser tóxico tanto em animais não-ruminantes quanto em ruminantes, porém é mais tóxico entre os não-ruminantes como suínos, aves e préruminantes que têm sua capacidade carreadora de oxigênio reduzida, o que resulta em respirações mais curtas e em edemas pulmonares (GADELHA et al., 2014).

Para Pons et al. (1953), a formação de gossipol é influenciada por diversos fatores como, as condições meteorológicas e pelas próprias espécies de algodão. Dessa mesma maneira os mesmos autores informam que ao considerar as 
condições climáticas, a formação de gossipol na planta é positivamente correlacionada com o índice pluviométrico e negativamente correlacionada com temperatura.

Portanto, devido a alta ocorrência de intoxicação em animais por gossipol, vários métodos têm sido apontados para mensurar os teores desse composto tóxico na produção dos alimentos à base de caroço do algodão, bem como a verificação de fatores climáticos e espécies de algodão (GUIMARÃES JÚNIOR et al., 2008). O objetivo deste trabalho é relatar um caso de óbito de bezerro decorrente de intoxicação por gossipol, comparado a outros casos relatados na literatura.

\section{RELATO DE CASO}

Foi atendido no Hospital Veterinário $(\mathrm{HV})$ da Universidade ParanaenseUNIPAR, no dia 24 de abril de 2017, um bovino macho, sem raça definida, com 25 dias de idade. Durante a anamnese o proprietário relatou que o animal estava sendo alimentado com ração que continha na composição caroço e farelo de algodão, que há sete dias o animal havia sido medicado para Babesiose e nos últimos três dias o animal veio apresentando piora, passando a ser tratado com penicilina e que, sem ter melhora, resolveu levar o animal doente ao HV.

No exame clínico apresentava sinais de acentuada desidratação e discreta icterícia de mucosa oral, prepucial e esclera; letargia; temperatura corporal $38,5^{\circ} \mathrm{C}$; na auscultação apresentava sons pulmonares anormais compatíveis com edema pulmonar ou excesso de secreção; não apresentava tosse nem secreção nasal. O animal foi a óbito, em seguida encaminhado para a necropsia, e na abertura do cadáver foi encontrada discreta icterícia de subcutâneo, observou-se também que o sangue coagulou lentamente na exposição ao ar e a musculatura dos membros torácicos e pélvicos estavam moderadamente pálidos.

Nos exames macroscópicos (Fig. 1) na cavidade torácica encontrava-se 88 $\mathrm{mL}$ de líquido na cavidade de coloração avermelhada. Por todo o trato respiratório apresentou líquido aerado e material mucopurulento, assim como o mesmo material foi observado em brônquios terminais. Os pulmões encontram-se, pesados, brilhantes, colapsados e com áreas de atelectasia, caracterizando um acentuado edema pulmonar. Notou-se $10 \mathrm{~mL}$ de fluido de coloração límpida no saco pericárdico e no folheto pericárdio fibroso, observou-se acentuado espessamento, áspero, com aspecto grosseiro e depósitos de fibrina. No coração constatou-se acentuada palidez, o epicárdio possuía fibrina aderida ao tecido.

No exame da cavidade abdominal notou-se $500 \mathrm{~mL}$ de líquido de coloração avermelhada. O baço apresentou acentuada esplenomegalia e congestão esplênica, discreto aumento dos linfonodos e edema no mesentério e na mucosa intestinal. No exame do fígado verificou-se moderada hepatomegalia e coloração vermelho acastanhado com distribuição difusa no parênquima da face diafragmática hepática, e também discreto espessamento da parede da vesícula biliar.

No sistema digestivo foi observada discreta hiperemia de abomaso e conteúdo de leite, aumento dos linfonodos e edema de mesentério e na mucosa intestinal. No exame histológico (Fig.2) mostrou no fígado infiltrado inflamatório linfoplasmocítico peri veia centro lobular, trombo em veia centro lobular, infiltrado mononuclear, congestão de veia centro lobular, discreta e multifocal necrose de hepatócitos. 
No saco pericárdico, em folheto fibroso, observaram-se células inflamatórias com predomínio de linfócitos infiltradas na superfície do folheto e, em algumas áreas, foram encontradas necrose e calcificação distrófica na cápsula. No epicárdico, região pericárdio parietal, observou-se em camada mesotelial células inflamatórias com predomínio de linfócitos infiltrados na superfície do folheto, em algumas áreas encontrou-se necrose de epitélio pavimentoso simples e calcificação distrófica.

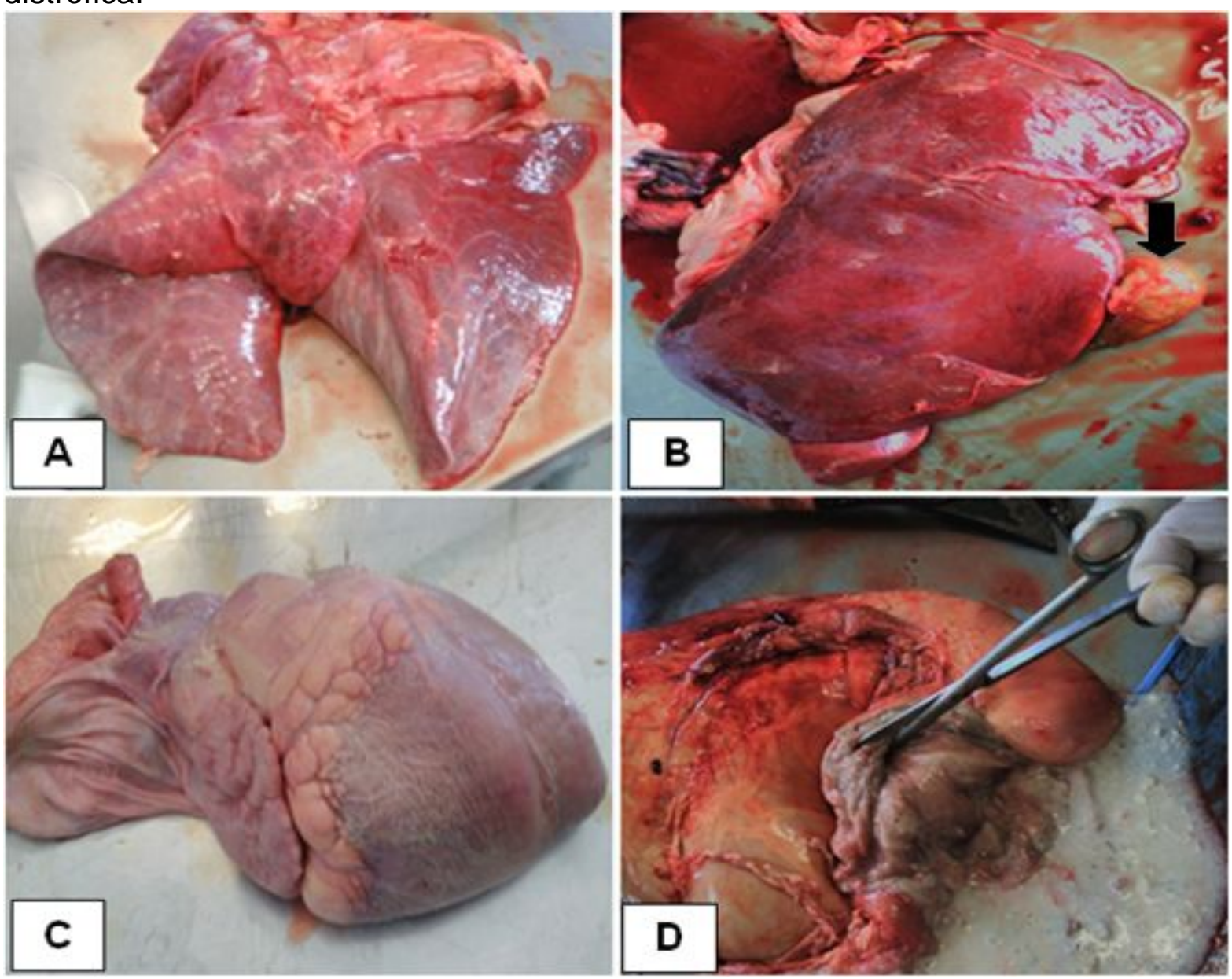

FIGURA 1. Achados de necropsia de um bezerro com intoxicação por gossipol: A - Os lóbulos consolidados possuem uma limitação cranioventral apresentando coloração vermelha escura, onde fluiu sangue ao corte. B - Fígado apresentando hepatomegalia. Seta preta indicando vesícula biliar. C - Coração junto com o saco pericárdio apresentando palidez e depósito de fibrina. D - Abomaso com conteúdo de leite. 


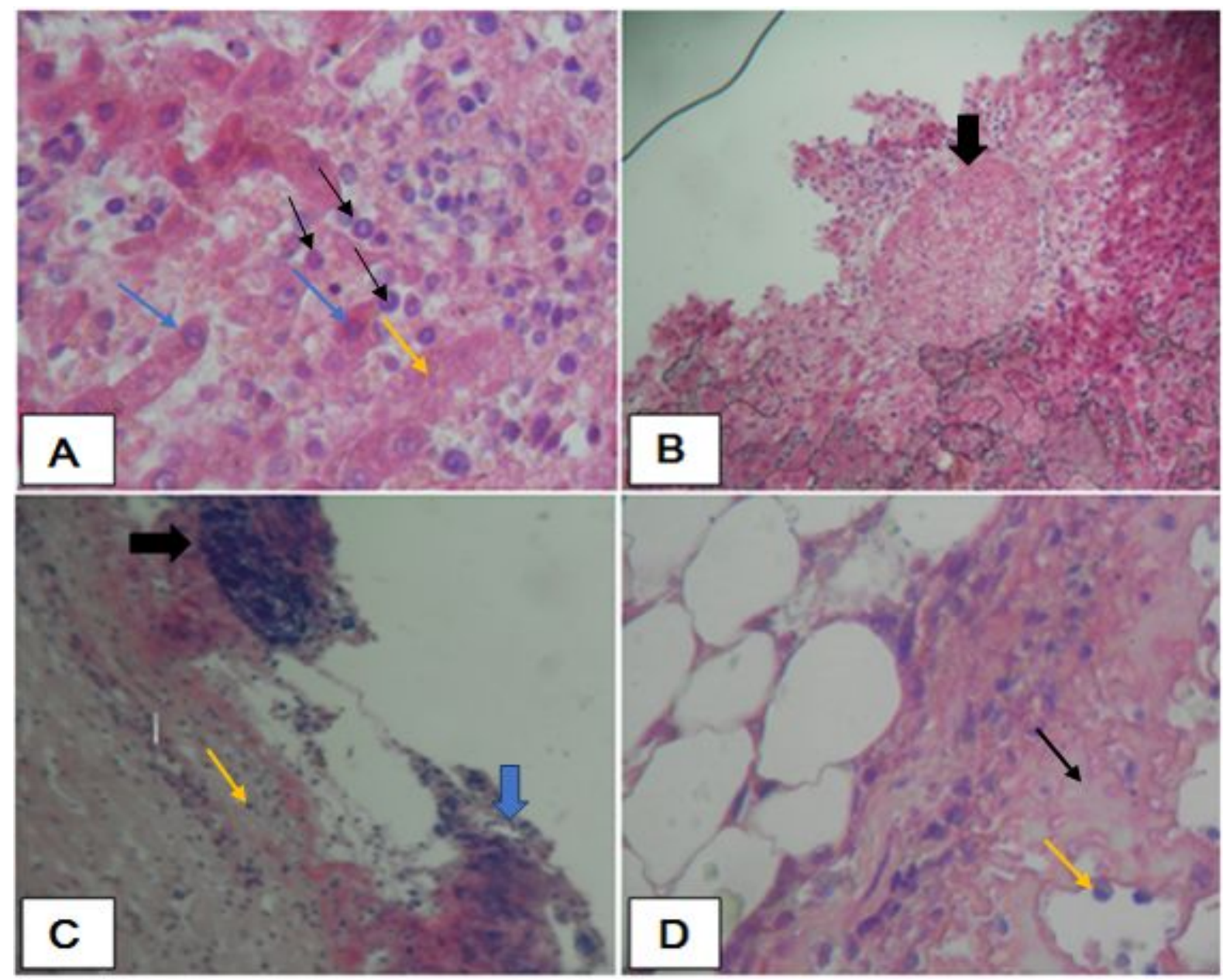

FIGURA 2. Achados histológico de um bezerro com intoxicação por gossipol: A - Fígado com o aumento de 40x, indicando em seta preta presença de Leucócitos; setas azuis hepatócitos degenerado e seta amarela áreas de necrose. B - Fígado no aumento de 10x, seta preta indica a presença de um trombo em veia centro lobular. C - Saco pericárdio em um aumento de 10x, onde a seta preta indica calcificação distrófica, seta azul áreas de necrose e a seta alaranjada infiltrado inflamatório. D - Epicárdico, em um aumento de 10x, onde seta preta indica áreas de necrose e seta amarela presença de leucócitos.

\section{DISCUSSÃO}

$\mathrm{O}$ animal estudado no presente trabalho chegou ao HV apresentando sinais clínicos compatíveis com outros sinais já citados em trabalhos de casos de animais com suspeita de intoxicação por gossipol como icterícia de mucosas, letargia, sons pulmonares anormais, desidratação. Morgan et al. (1988), em um experimento com ovinos jovens divididos em grupos, alimentados por dieta que continha doses variadas de gossipol livre, relataram que o grupo que recebeu maior dosagem de gossipol começou a apresentar sinais clínicos de intoxicação. Na segunda semana, foram observados sinais de icterícia de membrana, depressão, dispneia, além de anorexia e morte aguda. Em um experimento com bezerros em dieta a base de farelo de algodão (HOLMBERG et al., 1988) os animais também apresentaram sinais clínicos compatíveis com este tipo de intoxicação. 
Segundo Piau Junior et al. (2016) em um experimento com novilhas da raça nelore de 20 meses de idade sendo alimentadas com diferentes dosagens, chegando até 1.500 ppm de gossipol na dieta por um período de 70 dias, não foi observada nenhuma alteração clínica. Resultados estes que corroboram com os achados por Gomes et al. (2014) que também trabalharam com a raça bovina por um período de 95 dias.

Outros estudos com ruminantes adultos mostram que estes são mais tolerantes aos níveis maiores de concentração de gossipol do que os pré-ruminantes (GADELHA et al., 2014), isso se dá pelo fato da microbiota ruminal promover ligações do gossipol livre com a lisina das proteínas solúveis, tornando o gossipol livre inativo (GOMES et al., 2014). Embora Paim et al. (2010), Santos et al. (2013), Saldanha e Belo (2016) apontem que essa toxicidade causa diminuição da fertilidade de reprodutores devido a interferência na qualidade do sêmen.

Não foi feita a dosagem da quantidade de gossipol presente na ração fornecida ao animal que veio à óbito. De acordo com estudos (HOLMBERG et al., 1988) o gossipol para pré-ruminantes é altamente tóxico. Para ruminantes adultos é importante considerar os níveis de gossipol livre na dieta a base de subprodutos do algodão (MOREIRA, 2008; MARSÍGLIO 2015; SALDANHA; BELO, 2016). Piau Júnior et al. (2016) utilizaram 1500 ppm de gossipol em novilhas nelore confinadas durante 70 dias e não observaram intoxicação crônica por gossipol nesses animais. Gomes et al. (2016) ao analisarem a qualidade da carne de bovinos, constataram que a dosagem de até 5.05/animal/dia não promove efeito adverso na performance nem mesmo na saúde do animal.

$\mathrm{Na}$ necropsia, notou-se discreta icterícia de subcutâneo, observou-se também que o sangue coagulava lentamente na exposição ao ar, foi observada presença de líquido na cavidade torácica, abdominal e saco pericárdio; lesões também citadas por Holmberg et al. (1988) em experimento com bezerros, quando observaram líquido avermelhado em tórax e fluido amarelo claro e viscoso em abdome, com presença de fibrina em ambas as cavidades; também notou-se icterícia de subcutâneo e coagulação do sangue em exposição ao ar e nos casos mais severos de hidrotorax também notou-se líquido no saco pericárdico. Os pulmões se apresentaram pesados, brilhantes, colapsados e com áreas de atelectasia; e fluiu sangue ao corte da faca, o que representa edema pulmonar.

Morgan et al. (1988) evidenciaram diferentes graus de edema pulmonar e congestão vascular no grupo de ovinos que consumiram maior quantidade de gossipol, em experimento com bezerros alimentados com gossipol o órgão que mais evidenciou edema foi o pulmão (HOLMBERG et al. 1988). Já no caso de estudo com ruminantes adultos, não apresentou alterações pulmonares (PIAU JUNIOR et al., 2016).

No coração, região do epicárdio e no saco pericárdio no folheto fibroso foi observada acentuada palidez e depósito de fibrina, além dessas alterações também notou-se um aumento de peso do coração e depósito de fibrina em miocárdio e endocárdio. Em experimento com ovinos, Morgan et al. (1988) observaram alterações no saco pericárdio e epicárdio, foi observado microscopicamente infiltrado inflamatório e áreas de calcificação distrófica e necrose. Tanto nos achados microscópicos de Holmberg et al. (1988) quanto nos de Morgan et al., (1988) foram vistos vários graus de cardiomiopatias; degeneração e necrose das fibras 
musculares do coração. No experimento com bezerros houveram alterações no exame histopatológico de vários animais, aonde a maioria dos animais apresentaram separação das fibras musculares sugestivas de edema, poucos apresentaram degeneração aguda leve, um apresentou necrose e os bezerros que tiveram morte aguda apresentaram coração dilatado com áreas de palidez, edema intersticial, miócitos degenerativos e zonas perinucleares clara aumentadas (HOLMBERG et al., 1988).

O baço apresentou acentuada esplenomegalia e congestão esplênica, embora em um trabalho com ratos, foi visto uma redução do tamanho do baço (KITADA et al., 2008). Já em um estudo com suínos, foi relatada congestão esplênica (HASCHEK et al., 1989; SALDANHA; BELO, 2016) acarretando em esplenomegalia, discreto aumento dos linfonodos e edema em mesentério, e em mucosa intestinal. Holmberg et al. (1988) também evidenciaram edema de mesentério ao longo de todo o trato digestório. Em novilhas não foram vistas nenhuma dessas alterações (PIAU JUNIOR et al., 2016).

O fígado mostrou moderada hepatomegalia e coloração vermelho acastanhado, e também discreto espessamento da parede da vesícula biliar visto também em um experimento com bezerros (HOLMBERG et al., 1988), a microscopia mostrou um infiltrado inflamatório peri veia centro lobular com presença de trombo, degeneração e necrose de hepatócitos. Em ovelhas foi observado edema vascular em células hepáticas, necrose peri veia centrolobular, retenção de líquido biliar e degeneração gordurosa (HOLMBERG et al., 1988; MORGAN et al., 1988; EL SHARAK et al., 2010, FONSECA et al., 2013).

Segundo Carvalho et al. (2013) em um experimento com ratos foi observada: hepatite mista discreta a acentuada e degeneração moderada das células hepáticas. Foi relatada a presença de gossipol em tecido hepático de bezerros (HOLMBERG et al., 1988) e em ovinos jovens (MORGAN et al., 1988); em experimento com novilhas não foram observadas alterações macroscópicas, porém microscopicamente foi vista uma metamorfose gordurosa discreta a moderada, representando hepatite, (PIAU JUNIOR et al., 2016) comum em animais que consomem dieta contendo caroço de algodão (EL - SHARAKY et al., 2010).

Ainda no estudo de Holmberg et al. (1988) foram encontradas alterações nos rins que mostraram células necróticas em túbulos proximais, dilatação cortical e nefrite intersticial moderada. Nos achados de Morgan et al. (1988) mostram alta concentração de gossipol livre em tecido renal. Entretanto, no caso em estudo não foi encontrada nenhuma alteração significante nos rins, que pode ter ocorrido pelo fato da intoxicação ter se apresentado de forma aguda.

Nos experimentos citados na comparação com o caso em estudo, a quantidade ingerida pelos animais e a quantidade de gossipol existente no caroço de algodão eram medidas exatas. Apesar de os achados comprovarem a intoxicação do bezerro por gossipol, não se pode afirmar com exatidão a quantidade ingerida de ração e nem a quantidade de gossipol presente nesta ração. 


\section{CONCLUSÃO}

Os pré-ruminantes são mais susceptíveis à toxicidade do gossipol do que os ruminantes. Os principais danos nos pré-ruminantes são lesões em pulmão, coração, baço e fígado. Dependendo do teor de concentração do gossipol na ração e a quantidade ingerida pode acarretar em intoxicação aguda podendo levar à morte em poucos dias. Portanto, considera-se que o uso de ração contendo na composição subprodutos algodoeiros não é indicado na dieta de pré-ruminantes.

\section{REFERÊNCIAS}

BLANCO, B. S. Toxicologia Aplicada a Medicina Veterinária. Barueri: Manole, 2008.

CARDOSO, G. C. Utilização de subprodutos do algodoeiro na alimentação animal. 1998. Disponível em: <https://ainfo.cnptia.embrapa.br/digital/bitstream/item/91668/1/14265.pdf>

CARVALHO, W. L.; MENDES, L. C. N.; ROZZA, D. B.; MINGATTO, F. E. Mecanismos da intoxicação do fígado de rato causada pelo gossipol. Pesquisa Veterinária Brasileira, v. 33, n. 3, p. 339-344, 2013. Disponível em: <http://dx.doi.org/10.1590/S0100-736X2013000300011>

EL-SAIDY, D. M. S. D.; GABER. M. M. Use of cottonseed meal supplemented with iron for detoxification of gossypol as a total replacement of fish meal in Nile tilapia, Oreochromisniloticus (L.) diets. Aquaculture Research, v. 35, p. 859-865, 2004. Disponível em: <https://doi.org/10.1111/j.1365-2109.2004.01077.x>

EL-SHARAKY, A. S.; NEWARY, A. A.; ELGUINDY, N. M.; ELWAFA, A. A. Spermatotoxicity, biochemical changes and histological alteration induced by gossypol in testicular and hepatic tissues of male rats. Food and Chemical Toxicology, v. 48, n. 12, p. 3354-3361, 2010. Disponível em: $<$ https://doi.org/10.1016/j.fct.2010.09.004>

FONSECA, N. B. S.; GADELHA, I. C. N.; OLORIS, S. C. S.; SOTO-BLANCO, B. Effectiveness of albumin-conjugated gossypol as an immunogen to prevent gossypolassociated acute hepatotoxicity in rats. Food Chemical Toxicology, v. 56, p. 149-153, 2013. Disponível em: <https://doi.org/10.1016/j.fct.2013.02.010>

GADELHA, I. C. N.; FONSECA, N. B. S.; OLIRIS, S. C. S.; MELO, M. M.; SOTOBLANCO, B. Efeitos do gossipol na nutrição animal. Acta Veterinaria Brasílica, v.5, p.129-135, 2011. Disponível em: <https://doi.org/10.21708/avb.2011.5.2.2343>

GADELHA, I. C. N.; FONSECA, N. B. S.; OLIRIS, S. C. S.; MELO, M. M.; SOTOBLANCO, B. Gossypol Toxicity from Cottonseed Products. The Scientific World Journal, v.1, p.1-11, 2014. Disponível em: <http://dx.doi.org/10.1155/2014/231635>

GOMES, V. S.; MANO, S. B.; FREITAS, M. Q.; SANTOS, M. D.; CONTE JÚNIOR, C. A.; SILVA, J. M.; SANTOS, E. B. Meat characteristics of cattle fed diets containing 
whole cottonseed. Arquivos Brasileiros de Medicina Veterinária e Zootecnia, v. 68, n.4, 2016. Disponível em: <http://dx.doi.org/10.1590/1678-4162-8636>

GOMES, A. H. B.; SANTOS, M. D.; MURARO, L. S.; CAMARGO, L. M.; COSTA, D. S.; et al. Avaliação de parâmetros hematológicos e bioquímicos de touros submetidos a dietas com diferentes níveis de gossipol livre. Revista Brasileira de Higiene e Sanidade Animal, v. 8, n. 2, p.161-180, 2014. Disponível em: < http://dx.doi.org/10.5935/1981-2965.20140027>

GUIMARÃES JUNIOR, R.; MARTINS, C. F.; PEREIRA, L. G. R.; CARVALHO, M. A. Subprodutos da agroindústria na alimentação de bovinos: caroço de algodão. Planaltina, DF: Embrapa Cerrados, 2008, 33 p. Disponível em: $<$ https://ainfo.cnptia.embrapa.br/digital/bitstream/CPAC-2010/30396/1/doc-234.pdf>

HASCHEK, W. M.; BEASLEY, V. R.; BUCK, W. B.; FINNELL, J. H. Cottonseed meal (gossypol) toxicosis in a swine herd. Journal of the American Veterinary Medical Association, v. 195, n. 5, p. 613-615, 1989. Disponível em: < https://www.ncbi.nlm.nih.gov/pubmed/2777708>

HOLMBERG, C. A.; WEAVERW, L. D.; GUTERBOCK, W. M.; GENES, J.; MONTGOMERY, P. Pathological and toxicological studies of calves fed a high concentration cotton seed meal diet. Veterinary Pathology, v. 25, n. 2, p.147-153, 1988. Disponível em: <https://doi.org/10.1177/030098588802500207>

KITADA S.; KRESS C.L.; KRAJEWSKA M.; JIA L.; PELLECCHIA M.; REED J.C $\mathrm{Bcl}-2$ antagonist apo gossypol (NSC736630) displays single-agent activity in Bcl-2-transgenic mice and has superior efficacy with less toxicity compared with gossypol (NSC19048). Blood, v. 111, n. 6, p. 32113219, 2008. Disponível em: < https://doi.org/10.1182/blood-2007-09-113647>

MARSÍGLIO, B.N. Utilização de farelo de algodão na nutrição animal X gossipol. 2015. Disponível em: <http://iepec.com/utilizacao-de-farelo-de algodão-na-nutriçãoanimal-xgossipol> Acesso em: $21 \mathrm{ag} .2017$.

MOREIRA, F.B. Subprodutos do algodão na alimentação de ruminantes. Publicações em Medicina Veterinária e Zootecnia, v. 2 n. 36, 2008. Disponível em: <www.pubvet.com.br/material/Moreira20wf.pdf>

MORGAN, S.; STAIR, E.L.; MARTIN, T.; EDWARDS, W.C.; MORGAN, G.L. Clinical, clinic-pathologic, pathologic, and toxicologic alterations associated with gossypol toxicosis in feeder lambs. American Journal of Veterinary Research, v.49, n. 4, p.493-499, 1988. Disponível em: <https://www.ncbi.nlm.nih.gov/pubmed/3377308>

PAIM, T. P.; LOUVANDINI, H.; McMANUS, C. M.; ABDALLA, A. L. Uso de subprodutos do algodão na nutrição de ruminantes. Ciência Veterinária nos Trópicos, v.13, n. 1-3, p.24-37, 2010. Disponível em: <https://www.bvsvet.org.br/vetindex/periodicos/ciencia-veterinaria-nos-tropicos/13-(2010)-1-2-3/usode-subprodutos-do-algodao-na-nutricao-de-ruminantes/> 
PIAU JUNIOR, R.; RIBEIRO, E. de A.; QUESSADA, A. M.; RIBEIRO, E. de A.; ALMADA, A. F. B. Efeitos do gossipol em diferentes níveis na dieta de novilhas Nelore. Revista Brasileira de Medicina Veterinária, v.38, p.120-126, 2016. Disponível em:< http://rbmv.com.br/?link=verart\&tipo=ID\&campo1=1066>

PONS, W. A.; HOFFPAUIR, C. L.; HOPPER, T. H. Gossypol in Cottonseed, Influence of Variety of Cottonseed and Environment. Journal of Agriculture Food Chemistry, v. $1, \quad$ n. 18 , p.1115-1118, 1953. Disponível em: $<$ https://pubs.acs.org/doi/abs/10.1021/jf60018a007>

ROGÉRIO, M. C. P.; BORGES, I.; SANTIAGO, G. S.; TEIXEIRA, D. A. B. Uso do caroço de algodão na alimentação de ruminantes. Arquivos de Ciência Veterinária e Zoologia da UNIPAR, v.6, n.1 p.75-80, 2003. Disponível em: <https://doi.org/10.25110/arqvet.v6i1.2003.798>

SANTOS, M. D.; ROGRIGUES, R. S.; FREITAS, S. H.; COSTA, D. S.; RUAS, J. R. M. Qualidade seminal, morfologia dos testículos e epidídimos de touros submetidos à dieta contendo gossipol. Arquivos Brasileiros de Medicina Veterinária e Zootecnia, v. $65, \quad$ n. 4, p. 975-980, 2013. Disponível em: <http://dx.doi.org/10.1590/S0102-09352013000400006>

SALDANHA, I. C.; BELO, M. A. A. Gossipol: toxicidade dos produtos do algodão. Boletim Técnico da Universidade Brasil, Departamento de Produção Animal-23, 25p. 2016. Disponível em: <http://universidadebrasiledu.br/portal/wpcontent/uploads/2017/03/Boletim-t\%C3\%A9cnico-20-dezembro-de-2016.pdf>

YUE, Y.R.; ZHOU, Q.C. Effect of replacing soybean meal with cottonseed meal on growth, feed utilization, and hematological indexes for juvenile hybrid tilapia, Oreochromis niloticus x O. aureus. Aquaculture, v. 284, n. 1-4, p.185-189, 2008.

Disponivel em: <https://doi.org/10.1016/j.aquaculture.2008.07.030> 